\title{
Review of the Model Drawing Fine Arts Students Faculty Language and Art Medan State University
}

\author{
Mesra $^{1}$ \\ \{mesraa121@gmail.com\} \\ Faculty of Language and Arts, Universitas Negeri Medan, Indonesia ${ }^{1}$
}

\begin{abstract}
Model drawings for fine arts students focused on human objects, in portrait poses and full body. Based on observations on training tasks done by students, most of them had difficulty to achieve human face resemblance with the model being imitated. On the other hand, students are also in accurate in applying the proportion of human anatomy and draperies. The aim of the study was to find out the root of the problem of human model images that are difficult to achieve resemblance to the model being imitated. Then it was to know the accuracy of the application of proportions and draperies of cloth. The data collection technique of the research was by observing the students' drawing work in the final project. Observation accompanied by filling out observation sheets based on research variables. Documentation was conducted in the form of paper produced by the model, and photos of the model object being copied. Data analysis techniques used qualitative descriptive method. The results showed that $10 \%$ of the drawings achieved facial resemblance to the imitated model, the next 50\% were less similar, and the next $40 \%$ were not similar. The application of the theory of proportions shows that $20 \%$ of the results of the proportion with the right proportion, the next $50 \%$ is less precise, and the next $30 \%$ is incorrect. Dravery cloth on the results showed that $40 \%$ is right, the next $40 \%$ is not right, and the next $20 \%$ is not right. Analysis of the findings of this study revealed that the root of the problem was the finishing of imperfect arts (seen in lighting techniques the object was less plastic, the neatness of the image on the face elements is also less than perfect) and the weakness in displaying objects in perspective.
\end{abstract}

Keywords: Pfacial resemblance, proportion, dravery.

\section{Introduction}

The Drawing Model course is a compulsory subject for all art students. This course is a continuation of the Form Drawing course, and Plastic Anatomy. Model drawings can be used as a foundation for the creation of figurative paintings, and drawings with human objects. The Drawing Model course prepares students to be skilled at drawing humans realistically based on the model being imitated.

The results of the authors' observations show that most students are weak in their realist abilities from the start. Therefore, it is necessary to have a learning strategy that makes the mastery of drawing models easier. Realist images are always in demand by the public from the past until now. The ability to draw realistically is the minimum standard for an art student. This means that every student must be able or ready to fulfill every consumer demand, to describe or portray his portrait on a realist canvas. 
Some things that are suspected to be the cause of low student achievement in drawing models include:

a. The basic ability of drawing from new students is very low, due to lack of training during high school.

b. The frequency of student training drew a little model, because many other practical courses were also taken.

c. Students rarely analyze the work that is made, by comparing it to the theory of elements and art principles.

\subsection{Formulation of the Problems}

To reinforce the operational steps that will be implemented, the research problem can be formulated as follows:

1. How are the facial similarities in the results of the images imitated?

2. How does the proportion in the image refer to the model being imitated?

3. How does the dravery cloth in the figure refer to the model being copied?

\subsection{The Purposes of the Study}

1. To know the ability of students to achieve the similarity of images with the model being imitated.

2. To know the ability of students to apply the proportion of the right proportion based on the model being imitated.

3. To know the ability of students to display draveri fabrics based on the model being imitated.

\subsection{Research Contributions}

1. For students to accelerate mastery of model drawing skills

2. For students to improve learning outcomes (achievement index).

3. For lecturers as an increase in the ability to overcome problems that arise in the teaching and learning process (PBM), especially in the model drawing course

4. For the Department of Fine Arts and Higher Education as an improvement in the quality of out put.

\section{Literature Review}

\subsection{Definition of Drawing Models}

Drawing models means making imitation of objects or object models, in a flat plane with a tool that produces a clear trace, (TarjaSudjana et al. 2000. p. 1). Objects or object models in drawing models are human. Humans used as models vary in age and sex, such as children, adolescents, adults, parents, men and women. Drawing a model as if moving objects or object models onto the image field without any changes. So there must be a model object presented in front of the drawer. This means that when drawing objects without objects or models that are imitated, it is not called drawing models. 
Syafii, et al. (2003: 2.8) explained that drawing a model is an image that represents an object, in this case the object is human. Based on the two opinions above, it can be concluded that drawing a model is a representation of the human being presented before the drawing as a model. It means that the right image corresponds to the imitated object (representative representative).

The criteria for success in drawing a model is the similarity of the image according to the model object being imitated. There is no addition and subtraction of the characteristics of the object being observed. The composition of objects in the field of images is a condition of the beauty of an image, (Sipahelut, 1991: 87). Therefore the composition includes a part of evaluating the success of an image.

Shading (rendering) and paint strokes is a way of creating plasticity of image objects, so that the texture of the object image is clearly visible according to the model being imitated, (Sagala, 2003: 14). Shading is also useful in displaying image objects based on lighting on the model. Shading skill means the ability to apply dark light to the object image according to the lighting on the model with a scratch technique. Image clarity supports form accuracy. Form accuracy is the main requirement in drawing models.

Lighting of the object model can affect the observer's observation. Light coming from all directions, will interfere with observation and it is difficult to control the darkness of the object image and its shadow. Therefore, in drawing a model, it requires one direction of the dominant light source to the model object, so that it is clearly visible, and the shadow is also clear.

\subsection{Technical Model Practicum Drawing}

Practicum assignments are delivered at the beginning of the meeting, including the type of shading to be used, the direction of the illumination model, the expected image size, back ground of the requested image, and the time limit for completion. The model (object to be imitated) gets treated or arranged in such a way that it looks aesthetically pleasing. The student group (drawing) takes the position of sitting in front of the model object to form a semicircular pattern. One group consists of 5-7 students imitating one model (Tarigan, ibid).

The first stage of drawing is to determine the position of the drawing paper (horizontal / vertical) in accordance with the tendency of the model position in front. Assisted with a window view tool, the student will quickly determine the position of the drawing paper. The second stage is to set the outer edge of the drawing object (lay out) in the paper field, so that a harmonious composition is created (the image object is in the middle of the drawing area, not too small / not heavy, not heavy to the left / right / up / down).

The window view tool is made of a flat area such as thick cardboard or plywood, which is punched in the middle with a size of $4 \times 6 \mathrm{~cm}$, as a door or peeping space on the model object. The window view tool is used to help students observe the model through the window, so that it is easy to stitch images with the desired magnification scale.

The third stage is the taking of sketch drawings according to the proportions in the model. Magnification or reduction scale needs to be done because it adjusts to the size of the image area. Scale is obtained by comparing the size of the window view tool, compared to the area of the available image area. The fourth stage is doing color scaling or polishing to get the darkness of the object image and shadow according to the state of the model. Type of shading follows the image assignment instructions. 


\subsection{The Similarity of Images with Imitated Models}

Each persons draws a self portrait, required to achieve results similar to the original. In general, human faces have differences between one another, because God created the same human form. Likewise by drawing a person's face, the potential is very different from the original. Therefore, frequent training is needed, so as to achieve the imitation of the character of each face element properly.

The things that need to be considered to achieve similarity include: the initial sketch of the image must meet the accuracy of proportions based on the model being imitated, the lighting on the model must have one dominant direction of light, and understanding perspective drawing techniques.

\subsection{Proportion in Model Drawing}

Proportion is a size comparison of the parts that make up a single object, and also a comparison of sizes between several objects arranged in groups. For example the ratio of the width of the human shoulder is twice the width of the head, the distance between the left and right eye is once the width of the eye, the position of the eye line is half the height of the head, the height of the ear from the lower limit of the nose to the eye line, and so on. Size comparisons must be based on the right scale based on the model being imitated. For example a scale of 1:3 means that all elements of the object will be enlarged three times the original.

The success criteria in proportion is if the scale of enlargement or reduction in the image does not deviate from the comparison in the model. To get accuracy in zooming or even minimizing it needs to do repeated exercises. Each time the exercise should be carried out a scale comparison test with the existing model. The test includes every element that builds an object, such as the ratio of head height and width, distance between two eyes and eyebrows, nose length, mouth width, ear height and width, and overall head shape. In addition to the comparison of the elements that build an object, also seen the comparison with the environment, for example the ratio of human height to the seat height of the seat.

\subsection{Dark light in Model Images}

Dark light is also called lighting technique in images. An object will be visible if there is light. So the process of seeing an object is the light that hits the object bouncing into the eyes of the person who sees it. This means that the object will be clearly visible when the reflected light of the object matches the eye's needs.

Dark light serves to give clarity to the image. Success in the application of dark light also depends on the skill of observing objects carefully. A very helpful way to overcome the difficulty of mastering this lighting technique is to treat the model. We recommend that there is only one dominant direction of light on the model, for example using a spotlight.

It is necessary to pay close attention to the reflection of light falling on the model, because there are parts that look glare or white on a shiny object, even though the object is dark, the shiny part still looks white. Besides shiny or slippery objects and transparent objects such as glass or plastic it also absorbs the bias color of objects that are around it. For example, the sunglasses used by the model can capture the red color around it. so that there are parts of the glasses that look red. Therefore the drawer must color with red, not based on logic the color is black. 
Dark light includes: dark light of the object image, and darklight of light as a shadow. The part of the model that is close to the direction of the arrival of the light will look brighter than the other parts. Changes in light from light to dark on the object image will form a plastic gradation, therefore the object looks more real. The shadows of objects falling to the floor, as well as those concerning other objects beside them will reinforce the shape of the object. Besides that the background also needs to be optimized in order to give clarity to the object in front. For example, soft-colored objects can appear with a dark background.

\subsection{Perspective in Model Drawing}

The principle of perspective must be applied in drawing models, because the main requirements for drawing a model are to imitate the right shape based on observations (visual) of the existing model. The perspective is the result of observing the eye (visual) on an object where the part close to the eye looks bigger, taller, longer or wider, compared to the part that is farther from the eye. For example, the face of the model is observed from a three-quarter point of view, so the model's eyes don't look as big, the one closer to the observer looks bigger than the other. To obtain accuracy in the application of perspective, it is necessary to practice observing the model in detail in parts. In addition to the perspective of differences in size, there are also perspectives on differences in darkness, namely the closer part is more clearly visible, farther and more blurred.

\section{$3 \quad$ Research Method}

The research location is in the Department of Fine Arts, Medan State University. The reason for choosing this location was because the condition was directly experienced by students in the lecture drawing model. The population of this research is all the model drawing works made by students as the final project of the 100 model drawing subjects. Samples were taken sampling randomly by $60 \%$ of the population, so that 60 works were obtained.

Data collection techniques use observation sheets to assess the quality of the application of composition, proportion, and perspective of the object image.The data analysis model uses the Miles and Huberman theory (TjetjepRohendiRohidi 1992: 20 translation) as follows :

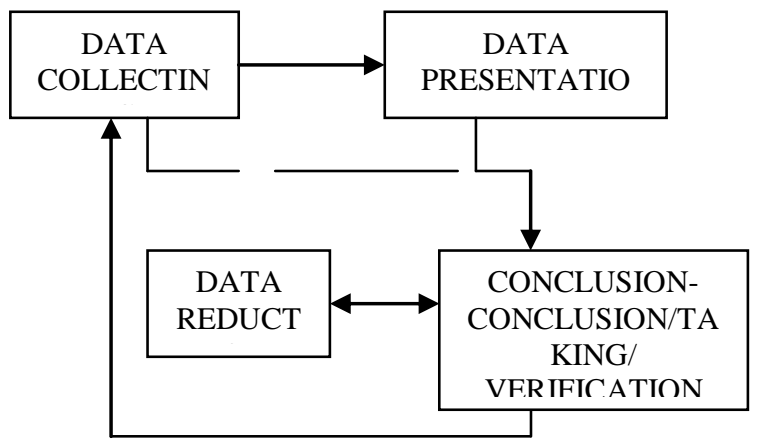

Fig. 1.collected data

After data is collected, data tabulation, data analysis, and data interpretation and conclusions are carried out 
The research design can be described as follows:

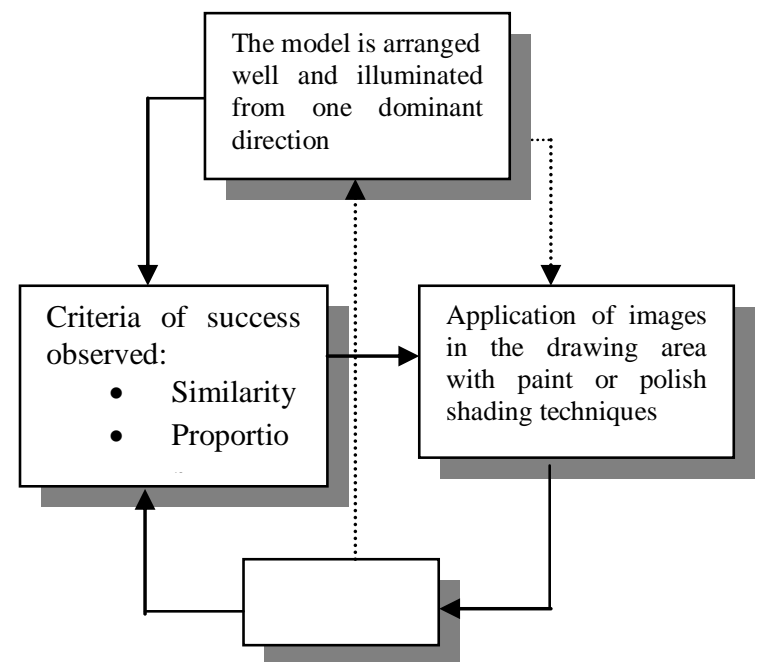

Fig. 2.design of the research

\section{Results}

1. The results of the study toward similarities, showed that $10 \%$ of the results of images achieved facial resemblance to the model being imitated, the next 50\% was less similar, and the next $40 \%$ was not similar.

2. The results of the study on the application of the theory of proportions, showed that $20 \%$ of the results of the image with the right proportions, the next 50\% was less precise, and the next $30 \%$ was incorrect.

3. The results of the study on the application of dravery cloth, showed that $40 \%$ of the dravey was right, the next $40 \%$ was not right, and the next $20 \%$ was not right.

\section{Discussion}

Less success of most students, in achieving finishing work that is very similar to the model, is influenced by various constraints, including internal factors and external factors. Internal factors such as the low basic skills of drawing students, before taking part in the model drawing lecture. External factors, including the lack of time for drawing exercises, drawing studio facilities had not been equipped with special lights for model recognition, and it was not well implemented in the form of criticisms and suggestions. 


\section{Conclusion}

1. Very few images of models that achieve similarity (representative realists) of the model being imitated, and many images are far from similar.

2. There were still a few students who are able to display the proportion of humans, precisely based on the model being imitated, and quite a lot are close to right.

3. Quite a lot of students have been able to display dravery based on the nature of the fabric, but still less firm than the lighting.

\section{Suggestions}

In order that students can master the model drawing skills well, the following are suggested:

1. Students should exercise model drawing more often so that they are able to observe in detail the model objects

2. Students should appreciate / discuss the work more often, along with criticism and suggestions for improving the results of the drawing.

3. Department of Fine Arts or Institutions in order to prepare all supporting factors or specific teaching and learning facilities needed in the model drawing course.

4. Other researchers may be able to carry out experimental research with special treatment or trial of special design teaching-learning methods for drawing models.

\section{References}

[1] Murtihadi, dkk. Dasar-Dasar Menggambar. Depdikbud. Jakarta. (1980).

[2] Sagala, Sofyan.. Menggambar Illustrasi. Seni Rupa FBS Universitas Negeri Medan, Medan. (2003)

[3] Sipahelut, Atisah.. Dasar-Dasar Desain. Depdikbud. Jakarta. (1991)

[4] Sudjana, Tarja. Dkk..Seni Rupa Untuk SLTP Kelas I. Penerbit Grafindo Media Paratama. Jakarta. (2000)

[5] Syafii.Dkk. Materi dan Pembelajaran Kertakes SD. Pusat Penerbitan Universitas Terbuka . Jakarta. (2003)

[6] Tarigan, Nelson.. Menggambar Model. SeniRupa FBS Universitas Negeri Medan, Medan. (2001)

[7] Wang, C. Thomas, Sketsa Pensil. Terjemahan Hendro Sangkoyo. Penerbit Erlangga. Jakarta. (1985). 